\title{
Los animales fieros en el Infierno de los enamorados del Marqués de Santillana.
}

\section{The wild beasts in Infierno de los enamorados by Marqués of Santillana.}

\author{
Esta obra está bajo una Licencia Creative Commons Atribución 4.0 Internacional. \\ DOI: $10.32870 /$ sincronia.axxii.n74.16b18
}

\author{
Clemente Aurelio Sánchez Rodríguez \\ Universidad Nacional Autónoma de México \\ clementeyue@hotmail.com \\ (MÉXICO)
}

Recibido: $31 / 03 / 2018$

Revisado: $23 / 04 / 2018$

Aprobado: $14 / 06 / 2018$

\begin{abstract}
RESUMEN
Durante la Edad Media, el Infierno fue recurrentemente representado de distintas formas y con diversos elementos en su interior, uno de ellos fue la Boca Devoradora que simulaba la entrada a través de un animal que tragaba a los condenados hacia su destino. Aunque este elemento fue muy notable en la pintura de esa época, en la literatura también se puede rastrear su presencia. Así, en la Baja Edad Media, un poeta de la Península Ibérica, don Íñigo López de Mendoza, o mejor conocido como el Marqués de Santillana, escribió un poema titulado Infierno de los enamorados, en el que se advierte el uso de la Boca Devoradora por medio de un grupo denominado "animales fieros", mismo que está conformado por leones, serpientes, tigres y dragones. El análisis simbólico de cada animal permitirá relacionar a cada uno con la entrada abrupta del Infierno.
\end{abstract}

Palabras clave: Boca Devoradora. Infierno. Animal. Símbolo. Entrada.

\section{ABSTRACT}

During the Middle Ages, Hell was often represented in many ways and with different elements inside, one of them was The Devouring Mouth that simulated an entry through an animal who swallow the condemned to their destiny. Even though this element was very present in time's painting, it can also be tracked it's presence in literature. So, in the Middle Ages, an Iberic Peninsulan poet, don Íñigo López de Mendoza, or better known as Marqués de Santillana, wrote the poem titled Infierno de los enamorados, in wich he warns the use of the Devouring Mouth by a group called "wild beasts" 
conformed by lions, snakes, tigers and dragons. The symbolic analysis for each animal will allow relating each one with its abrupt entry to Hell.

Keywords: Devouring Mouth. Hell. Animal. Symbol. Entry.

\section{La fauna del Infierno}

En sus inicios, el Infierno era sólo un espacio inframundano al que se dirigían todas aquellas almas que habían pasado de la vida a la muerte. Esta idea de un único lugar para los muertos se expresó en diferentes culturas antiguas; en la romana, por ejemplo, la Eneida de Virgilio mostraba un Aqueronte no sólo plagado de los difuntos, sino también de una importante presencia de seres monstruosos como los centauros, quimeras y arpías que le daban a este espacio una característica aún más tenebrosa. Aunque éstos no eran animales como tal, existía, no obstante, un interés por poner en el inframundo seres que cumplieran la función de ser guardianes y, al mismo tiempo, de convertir tal morada en un lugar monstruoso. Por su parte, en la Biblia, aunque no hay una referencia directa al Infierno, sí había un espacio al que se dirigían los muertos, conocido como el Seol; precisamente, una de las criaturas que se ubica ahí es Leviatán, bestia que aparece por primera vez en el libro de Job (40:15), mientras que en Isaías (27:1) es descrito con rasgos de serpiente y dragón.

En estos breves ejemplos se observa un interés por dotar al inframundo con elementos terroríficos, con especial énfasis en bestias residentes de aquellas tierras. Con el paso del tiempo, esos animales se convirtieron en entidades imprescindibles para el Infierno. Para entender lo anterior, resulta necesario recordar que el uso simbólico de la fauna en el Medievo fue muy importante, pues tanto los emisores, como los receptores de las obras, codificaban el símbolo del animal en relación con el tipo de espacio en el que aparecía. De este modo, los animales más salvajes fueron los predilectos para representarse en el Infierno. Al respecto, Jacques Voisenet comenta:

El animal sirve para tranquilizar al hombre y comprender que la Creación es una obra total de la que él forma parte. Incluso cuando la bestia pertenece al registro del miedo, 
amenazando su integridad física y espiritual, proporciona un mayor valor, por oposición, a la armonía y la paz que gozan los que viven de acuerdo con Dios. Busca con ello darle confianza instruyéndole plenamente sobre los peligros de la vida, sobre los abismos que debe evitar y las cimas que tiene que subir (Voisenet, 2012, p. 204).

Las palabras del autor son interesantes, pues afirman que mientras el animal representado tuviera más carga negativa, mayor era el impacto causado en los receptores de la obra en cuestión. Por tanto, en el caso del Infierno, la fauna presente en este espacio advertía a los creyentes sobre los tipos de castigos dolorosos a los que se enfrentarían si no llevaban una vida libre de pecados. Lo anterior también lo señala Nora Gómez:

Los iluminadores medievales apostaron a la fuerza expresiva, a la naturaleza amenazante y destructiva de las fauces devoradoras, confiaron en su impacto dramático y supieron encontrar el medio idóneo para darle forma a la infigurabilidad del Infierno y vehiculizar por medio de la imagen punitiva el uso doctrinal de las artes visuales que implementara la Iglesia como medio de adoctrinamiento, como modo de interpelar al receptor para hacerlo reflexionar acerca de las consecuencias del alejamiento del dogma (Gómez, 2010, p. 274).

En efecto, a través de la pintura fue como el Infierno y sus elementos simbólicos adquirieron mayor impacto en los receptores; así pues, los animales que torturaban a los condenados mostraban las consecuencias de los malos actos que ofendían a Dios. De modo que existió una fauna muy recurrente para las representaciones del Averno durante la Edad Media; este tipo de animales debía contener un significado nocivo para la mentalidad medieval, ya fuera por sus rasgos físicos, ya por su significado simbólico posiblemente relacionado con la tradición del Fisiólogo o los Bestiarios. Considerando lo anterior, cabría preguntarse: ¿Cuáles eran las animalias más constantes en el Infierno? Ángela Muñoz señala: 
En suma, la fauna de la gehena está constituida principalmente por animales mordientes y feroces cuyos dientes o cuernos destrozan las carnes culpables: reptiles, insectos, gusanos o abejas. La fauna infernal la componen seres de los confines que se sitúan en los límites de los mundos subterráneo y de superficie, celeste y terrestre. Estas apariciones de tema animal tienen una función disciplinaria y moral que designa los buenos y los malos comportamientos. La presencia de estos animales responde a tres grandes ejes de significado: el sufrimiento físico que infligen, el horror que suscitan - serpientes y gusanos aparecen constantemente en todas las evocaciones del Infierno - y la vergüenza que despiertan en los culpables caídos en el nivel más bajo de la Creación. Esta fauna infernal tenía como finalidad bien suscitar miedo, bien proporcionar una toma de conciencia del peligro que amenazaba a la persona (Muñoz, 2012, p. 363).

De acuerdo a las palabras de la autora, los animales utilizados para darle mayor efecto simbólico al Infierno fueron aquellos que contaban con rasgos agresivos, principalmente los que tenían colmillos o cuernos para torturar a los prisioneros. Bajo tales preceptos, posiblemente los animales infernales adquirieron una de sus máximas representaciones en la Boca Devoradora, pues ese nuevo elemento constituía ni más ni menos que la entrada al Infierno, la antesala de la morada de Lucifer y el primer paso a una estancia llena de eternos castigos. Según Nora Gómez, tal representación tuvo su origen: "en los primeros decenios del siglo XI los monjes anglosajones optaron por representarlo como una boca bestial devoradora" (Gómez, 2010, p. 273). En efecto, la función que tiene la Boca feroz del Infierno es la de tragar a los nuevos condenados, como una metáfora del sufrimiento eterno que les espera en el interior del Averno.

La principal característica de la Boca Devoradora residía en simular la mordedura de un animal salvaje, que mastica a todos los nuevos condenados y les hace sentir el dolor de los colmillos, así como el de las llamas dentro del hocico. Por tanto, para este elemento tan importante se debía pensar en ciertas bestias que simularan el acto de devorar ferozmente. Con base en lo anterior, hubo una notable preferencia por los leones para la Boca, pues éstos tienen todos los 
rasgos físicos para la devoración: "el león que acecha y desgarra, también homologado con la fuerza devoradora de Satán. Las fauces y cabezas leoninas llegaron a ser el modo dominante de la Boca del Infierno" (Gómez, 2010, p. 273). Los leones fueron con recurrencia los animales que mostraron la entrada terrorífica del Averno, por lo que su fiereza y los colmillos serán sus rasgos más destacados.

Otra bestia recurrente en las pinturas de la Boca Devoradora es el dragón. Éste, tan emparentado con la serpiente, guarda características físicas monstruosas y agresivas suficientes para representar una tortura impactante en la entrada del Infierno. Según San Isidoro: “El dragón es la mayor de todas las serpientes, e incluso de todos los animales que habitan en la tierra" (Sevilla, 1982, p. 81). La relación entre el dragón y la serpiente durante la Edad Media contribuyó a que ambos fueran comúnmente caracterizados como entidades demoniacas, de ahí que Ángela Muñoz proponga:

En términos generales, la serpiente y el dragón fueron animales identificados con el diablo y por extensión con el mal en muchas tradiciones escatológicas y apocalípticas. Las serpientes policéfalas y el dragón fueron también dos de las presencias animales más características de los espacios infernales en las tradiciones apocalípticas cristianas (Muñoz, 2012, p. 353).

Como se observa, la Boca Devoradora era ilustrada por una serie de animales que compartían los rasgos de ser feroces. La fauna predilecta para representar la Boca era, sobre todo, compuesta por felinos y reptiles. Respecto a la bestialidad de estas animalias, Penélope Izaguirre señala:

De tal forma que, en el contexto cristiano, los animales, posibles de imaginar con oscuros deseos o intenciones violentas y al servicio de la urbe del inframundo, no son compatibles con la armonía del universo, en suma, ya no son "animales", sino "monstruos", "bestias" o "fieras"; es decir, son un producto contrario al orden regular de la naturaleza y, como tal, generan una conveniente acogida teológica y un particular rechazo estético. Así, el creador o escritor se encarga de fijar la monstruosidad y bestialidad de cada uno de ellos: 
por ejemplo, destacando en la fauna descrita las marcas más notables de la fiereza por medio de las fauces y los dientes (Fernández, 2016, pp. 135-136).

En efecto, la ferocidad del animal en el espacio infernal se deforma tanto que muestra la monstruosidad del ser, convirtiéndolo en una entidad contraria a la creación divina y, por ende, a la naturaleza; rasgos que congenian con el Infierno. Los artistas dieron mucha importancia a las facciones de los animales que ilustran la Boca Devoradora.

Estas características de la representación de la entrada infernal perduraron durante la Edad Media y, tal es así, que incluso a inicios del siglo XV esas tradiciones se pueden rastrear en la literatura. El Marqués de Santillana, posiblemente el poeta más emblemático de la Península Ibérica de esa época, también se interesó en la imagen del Infierno en uno de sus poemas, de ahí que pretendo mostrar que en su texto, Infierno de los enamorados, existe una referencia a la Boca Devoradora por el tipo de animalias que se mencionan y que son denominados "animales fieros".

\section{La Boca Devoradora del Infierno de los enamorados}

El Infierno de los enamorados narra el arrebato del personaje por parte de la diosa Fortuna para emprender un viaje al Más Allá. A lo largo de su recorrido por este espacio, el "yo" lírico ve y se enfrenta a distintos animales, entre los cuales destaca un fiero jabalí. Cuando esta bestia está a punto de atacarlo, aparece Hipólito con vestiduras de caballero y mata al puerco. Hecho esto, el personaje mitológico se convierte en guía del "yo" lírico para llevarlo a un castillo rodeado de fuego en el cual se ubica el Infierno de Amor.

Como se puede apreciar en la descripción, existen dos espacios dentro del poema de Santillana: el del Más Allá y el Infierno. Debido a que ambos lugares son infraterrenales y, por tanto, de condena, resulta interesante que Santillana haya utilizado distintos animales para caracterizar su 
texto. ${ }^{1}$ Debido a los rasgos físicos de cada animal, parece que Santillana conocía muy bien la tradición cultural de sus bestias infernales. Así pues, los animales fieros constituyen el primer contacto que tiene el "yo" lírico con el Más Allá y, al mismo tiempo, con la fauna de todo el poema. El breve fragmento del texto es el siguiente:

Muchos fieros animales

se mostravan e leones,

e serpientes desiguales,

grandes tigres e dragones:

de sus diversas façiones

non relato por estenso,

por quanto fablar inmenso

va contra las conclusiones (Santillana, vv. 41-48).

Para comenzar con el análisis de estos versos, resulta oportuno recordar la caracterización de Penélope Izaguirre (2016) en la que se explica que las fieras representan un contrapunto de lo establecido en la naturaleza, con lo que tal fauna está ligada a la maldad del Infierno. En efecto, Santillana, al ocupar el término "fieros animales", advirtió sobre la característica del espacio al que el "yo" lírico llegará: uno donde existe la condena amorosa. Como conjunto, se observa que este grupo de animales fieros está conformado por dos felinos y dos reptiles; precisamente, como ya se pudo apreciar anteriormente, éstos son los tipos de bestias que imperaban en las representaciones de la Boca Devoradora.

La propuesta de análisis sobre que este grupo de animales simboliza la Boca Devoradora del Infierno de los enamorados reside, además de otras características particulares de las animalias, en que dicha agrupación se ubica justo al principio del viaje del "yo" lírico. Para ello, cabe recordar que

\footnotetext{
${ }^{1}$ Dentro del poema, además del grupo de "animales fieros" que a continuación se presenta y, como ya se mencionó, del jabalí, también existen en el texto otras animalias, como son, en orden de aparición: un halcón, un caballo, un perro y un águila.
} 
la Boca infernal, en las representaciones medievales, simbolizaba el primer castigo que los pecadores debían experimentar para su llegada al Infierno; del mismo modo, este conjunto de animales en el Infierno de los enamorados marca el viaje del protagonista por medio del horror de las descripciones de las fieras, como si se tratara de una condena visual.

Para entender lo anterior, hay que resaltar que, aunque los animales mencionados no son descritos de forma detallada, sí se aprecian adjetivos que los posicionan como nocivos y salvajes. Por ejemplo, las serpientes son caracterizadas como "desiguales", es decir, desproporcionadas; los tigres y dragones son "grandes", lo que indica que son bestias de enorme tamaño. A decir de Penélope Izaguirre: "De ahí que, para lograr la eficacia del mensaje en la narración, la apariencia del animal tiene que ser extremadamente feroz y demoniaca; no olvidemos que el animal, visto así, es enemigo de Dios y del hombre" (Fernández, 2016, p. 126). Con dicha explicación, se confirma que los animales fieros que hay en el texto de Santillana advierten el peligro y el contrapunto de la naturaleza divina con respecto a la presencia infernal que más adelante se desarrollará en el texto.

Como conjunto, este grupo funciona muy bien para significar el acceso al Más Allá, pero es a través de los rasgos particulares de cada uno de sus animales con lo que se puede reflexionar mucho mejor si éstos conforman o no una alusión a la Boca Devoradora. Por esta razón, a continuación se presenta el análisis simbólico de cada una de las bestias.

Al seguir la jerarquía de los fieros animales en el poema, los leones son los primeros que se mencionan. Aunque el león durante la Edad Media era comúnmente asociado a la figura de Cristo y a la bondad, su propiedad nociva ya tenía antecedentes respecto al inframundo, así lo explica Angelo de Gubernatis: "El león monstruoso, que guarda el antro del monstruo, la morada infernal, se menciona en un gran número de cuentos populares" (Gubernatis, 2002, p. 428). El comentario del autor es interesante, pues señala que el león de terrible aspecto resulta un rasgo típico de las entradas infernales y, como tal, se le considera un guardián de dicho espacio. Sin embargo, más allá de sus significados benefactores o negativos del león, Deyermond expone lo siguiente con respecto a la referencia de dicho animal en esta época: 
Hay muchos animales que tienen su capítulo en el bestiario pero que se ven cada día en la calle o en el campo: el perro, el gato, el caballo, la oveja, el gallo se mencionan en la literatura y se representan en la iconografía con frecuencia que corresponde a su familiaridad en la vida, y sería absurdo (si no hay coincidencias textuales) suponer que su presencia en la literatura o en el arte se debe al bestiario. El león está a medio camino entre estos dos grupos de animales: no se veía en el campo en la Europa medieval, pero era tan conocido como el rey de los animales (más estrictamente, de los mamíferos) y aparece tantas veces en la Biblia que la mayoría de las alusiones a los leones son más o menos automáticas (Deyermond, 2007, p. 46).

En efecto, en la mayoría de los Bestiarios las descripciones del león lo asimilan a un ente bueno; sin embargo, aunque Santillana pudiera o no estar familiarizado con tales textos, es más probable que la mención del león en su grupo respondiera a un proceso automático de saber colectivo, en tanto animal considerablemente conocido y citado, sobre todo para los Infiernos literarios. Así, la posición del león en el grupo no es casual, pues, por su rasgo de rey de las bestias, dicho animal debía encabezar este conjunto de entes salvajes. Sumado a esto, debe recordarse que en las representaciones de la Boca Devoradora el león era el animal más usado para tal motivo, por lo que se considera que existe una intención poética para ubicar al felino en el inicio de los animales salvajes que observa el protagonista del Infierno de los enamorados.

Lo anterior es muy interesante si se piensa que otro poeta anterior a Santillana ya había utilizado la misma referencia a un león salvaje para el inicio de un viaje al Infierno. Evidentemente se trata de Dante, cuya Divina Comedia fue la pieza clave para que Santillana desarrollara su Infierno de los enamorados. El inicio de la Comedia de Dante es caracterizado por la presencia de tres animales feroces: un leopardo, un león y una loba. El rasgo salvaje es lo que más define a estas 
animalias en el texto del florentino, de ahí que es viable pensar que Santillana retomara el recurso del león nocivo. ${ }^{2}$

A continuación de los leones, se encuentran las serpientes. En la descripción respecto a esos seres es claro que se intenta precisar la monstruosidad física de la bestia en cuestión. En el contexto del grupo animal nocivo, la serpiente no podía faltar debido a su profunda relación con Satanás, la cual está fundamentada en la Biblia (Génesis, 3:14); además de esto, hay que recordar que Ángela Muñoz señala que el tipo de fauna del Infierno destaca por estar en el límite de lo terrestre y subterráneo, de ahí que este animal sea recurrente en los espacios inframundanos, como lo muestra la Divina Comedia en el canto XXV con las serpientes que enrollan a los pecadores.

Después del rey de los animales de la tierra, la serpiente tiene una posición prioritaria por su imagen y significado nocivo, razón por la que el Marqués de Santillana pudo jerarquizar a estas dos bestias en el Infierno de los enamorados de acuerdo a su negatividad simbólica. Como bien explica Cirlot sobre el significado del reptil:

Esto explica que Blavatsky diga que, físicamente, la serpiente simboliza la seducción de la fuerza por la materia (Jasón por Medea, Hércules por Onfale, Adán por Eva), constituyendo la manifestación concreta de los resultados de la involución, la persistencia de lo inferior en lo superior, de lo anterior en lo ulterior, lo cual es ratificado por Diel, para quien la serpiente es símbolo, no de la culpa personal, sino del principio del mal inherente a todo lo terreno (Cirlot, 2004, s.v. "serpiente").

En ese sentido, la serpiente representa la debilidad de la fuerza por la materia, así, en el caso del Infierno de los enamorados, se podría argumentar que es la seducción de la carne provocada por las

\footnotetext{
${ }^{2}$ Una relevante propuesta respecto a la función grupal que tienen los animales salvajes de Dante en la Comedia la expone Fernando Ibarra (2016), en la que reconsidera una reflexión de Guglielmo Gorni que explica que estas tres bestias podrían ser un símil del Lucifer dantesco, en tanto que simbolizan sus tres cabezas. Tal señalamiento es sin duda interesante, si se piensa que en la Comedia se describe que con cada boca Satanás mastica a los condenados, con lo que podría plantearse que, si los tres animales vistos en la selva son una posible significación de las cabezas de Lucifer ¿se tratarían entonces de una Boca Devoradora anticipada en la Divina Comedia?
} 
pasiones y los excesos del amor, con lo que se justificaría su presencia en el poema. Por otra parte, resulta interesante la referencia de los personajes mitológicos y bíblicos en la cita, pues son figuras emblemáticas de la seducción. Si esto se contrasta con el texto de Santillana, se obtiene que también en el Infierno del poeta español haya una relevante serie de personajes mitológicos que son, en efecto, los condenados del Infierno de Amor. Asimismo, se debe pensar en los rasgos físicos de la serpiente: es infraterrenal y tiene un hocico con colmillos venenosos; a partir de esto, de nueva cuenta se observa un animal idóneo para figurar una devoración hacia el Infierno.

El tigre es la bestia que prosigue a la serpiente. A través de su presencia se refleja la construcción que dio Santillana a su grupo de animales, pues en un ejercicio comparativo entre las fieras mencionadas en el Infierno del Marqués, el tigre se encontraría en una posición relacionada con el otro gran felino que es el león, al ser intercalado por la serpiente, con lo cual podría suponerse que, al existir una asimilación semántica y zoológica entre el león y el tigre, el Marqués de Santillana usó la figura del segundo para mantener una coherencia de tipología en el texto. Por otro lado, aunque el tigre no cuente con una amplia tradición simbólica en la literatura (a diferencia del león y la serpiente), es oportuno comentar que Juan de Mena también lo usó en su Laberinto de Fortuna dentro del conjuro de la maga, en el que caracteriza al felino como un ser fiero.

De manera que podría confirmarse que para que existiera una correlación de bestias en los animales fieros de Santillana, el tigre es el más cercano al león. Además, no hay que olvidar que en las representaciones pictóricas de las Bocas del Infierno los felinos tenían una gran prioridad para simular el temible hocico de la entrada, con lo que la existencia de dos felinos en el grupo del poema del Marqués reafirma la idea de la devoración que sufre el "yo" lírico. También, otro rasgo a destacar es que las bestias fieras expuestas hasta el momento comparten la característica de ser depredadores, por lo que se asevera más el hecho de que representen la Boca Devoradora del Infierno de enamorados.

Para cerrar el grupo de animales fieros, Santillana decidió usar al dragón. Como ya se comentó, tal bestia es una de las animalias más asociadas tanto a la imagen de Lucifer como al 
Infierno. Ello se comprueba en la pintura, específicamente en las representaciones de la Boca Devoradora en las que el dragón formó parte. También en la literatura esta bestia fue comúnmente asociada a la morada de Lucifer, por ejemplo, en la Divina Comedia de Dante se menciona a uno en el canto XXV del Infierno. Como expresa Michel Pastoureau: "Así como forma parte de la vida cotidiana el dragón, criatura del Diablo, símbolo del Mal que se halla en todas partes y que ocupa un lugar considerable en las mentalidades" (Pastoureau, 2006, p. 19). De nueva cuenta, el saber colectivo respecto al significado de la bestia fue posiblemente una de las razones por las que Santillana ubicó a este monstruo en tal grupo.

Asimismo, destaca la posición que tiene el dragón en el grupo, pues se ubica al final, como una suerte de culminación terrorífica de los animales fieros. Resulta importante mencionar que el dragón en la Edad Media fue considerado un ser que guardaba rasgos físicos de otros animales como la serpiente y distintos felinos, sobre todo el león. En ese sentido: “Un examen morfológico de los dragones legendarios nos autoriza a ver en ellos una suerte de confabulación de elementos distintos tomados de animales especialmente agresivos y peligrosos, serpientes, cocodrilos, leones y también animales prehistóricos" (Cirlot, 2004, s.v. “dragón"). De acuerdo a estas palabras, el dragón es una entidad híbrida, resultado de una serie de animales fieros y nocivos, por lo que no es de extrañar que Santillana pudiera considerar al dragón para combinar los aspectos negativos del grupo de animales fieros en ese monstruo. Por ende, el dragón que lanza fuego y posee unos colmillos terroríficos, similares a los de los felinos y las serpientes, bien puede ilustrar la Boca Devoradora existente en el Infierno del Marqués de Santillana.

De este modo, al observarse las características particulares de cada uno de los animales fieros del Infierno, se puede notar que, en conjunto, el león y el tigre, ambos terrenales y felinos, están relacionados entre sí, mientras que la serpiente y el dragón, infraterrenales y reptiles, también coinciden en sus rasgos semánticos, lo que prueba una coherencia poética por parte de Santillana para formar tal grupo de animales fieros. Aunque estos animales son poco descritos, a 
diferencia de los que versos más adelante ve el protagonista, este grupo de bestias salvajes resulta importante para la secuencia de la narración poética y para el sentido del mensaje.

Los fieros animales son el primer contacto que tiene el personaje con el espacio inframundano. Ellos no sólo advierten acerca del peligro del lugar al que el protagonista llegará, sino que, por su posición en la narración, considero que este grupo constituye una Boca Devoradora en el poema de Santillana. Ésta simula una entrada abrupta al Más Allá, caracterizada por leones, serpientes, tigres y dragones que devoran al "yo" lírico, lo que provoca un efecto de descenso hacia la parte más recóndita del Universo, es decir, el Infierno. De algún modo, Santillana debía formular en su poema una manera para que el protagonista cayera al Infierno de Amor y qué mejor que a través de la Boca Devoradora constituida, además, por distintos animales feroces y terroríficos.

La fauna nociva en el Infierno de los enamorados advierte no sólo a la voz poética, sino a los propios lectores acerca de los horrores del Infierno amoroso y, también, da indicios sobre el propio mensaje del poema: la condena de las pasiones. Resulta necesario recodar que en la Edad Media la fauna punitiva, puesta en la Boca Devoradora, generaba en los receptores un impacto necesario para provocar temor de las condenas del Infierno pero, más que eso, inspirar un sentimiento de creencia y deseo de salvación para acercarse a las lecciones religiosas.

En conclusión, las cuatro bestias en el poema de Santillana funcionan como el inicio brusco y salvaje del viaje poético, lo cual simula un descenso al Infierno de los enamorados, espacio tenebroso y oscuro, rasgos idóneos para la relación entre un lugar negativo y la fauna punitiva que observó el protagonista. La presencia simbólica de los animales y su estudio en la literatura permiten otras interpretaciones que tal vez, en una primera lectura, sería difícil de advertir sino fuera por una propuesta de análisis que se basa en aquellos seres que muchas veces se encuentran en los textos literarios y tan sólo los pensamos como meros recursos decorativos, pero que su enorme tradición cultural les dota de significaciones muy relacionadas a los mensajes de las obras, como se ha demostrado en este estudio del Infierno de los enamorados del Marqués de Santillana. 


\section{Referencias:}

Cirlot, J. E. (2004). Diccionario de símbolos. Barcelona: Siruela.

Deyermond, A. (2007). Leones y tigres en la literatura medieval castellana. Actas del XI Congreso Internacional de la Asociación Hispánica de Literatura Medieval, 41-63.

Fernández, P. M. (2016). “De los infiernos en la literatura hispánica medieval: el papel activo de la natura en la cosmovisión del mundo infernal", México: UNAM. Tesis.

Gómez, N. M. (2010). La representación del Infierno Devorador en la miniatura medieval, Memorabilia, (12), 267-287.

Gubernatis, A. de (2002). Mitología zoológica. Las leyendas animales. Los animales de la tierra. Barcelona: José J. de Olañeta.

Ibarra, F. (2016). Algunas reflexiones sobre la cuestión de "las tres fieras" en el Infierno de Dante. En Xochiquetzalli Cruz Martínez y Penélope Marcela Fernández Izaguirre (coords.). De animalibus: la presencia zoológica en la literatura (151-167). México: UNAM.

Muñoz, Á. (2012). Gusanos, serpientes y dragones. Fauna punitiva en las geografías del Más Allá. En Ma. Rosario García Huerta y Francisco Ruiz Gómez (dirs.). Animales simbólicos en la historia. Desde la Protohistoria hasta el final de la Edad Media (337-364). Madrid: Síntesis.

Santillana, M. de (1999). Poesía lírica, Madrid: Cátedra.

Sevilla, I. de (1982). Etimologías, t. II. Madrid: Biblioteca de Autores Cristianos.

Pastoureau, M. (2006). Una historia simbólica de la Edad Media occidental, Buenos Aires: Katz.

Voisenet, J. (2012). El pensamiento simbólico en la Edad Media. El simbolismo animal según los clérigos de la Edad Media. En Mar. Rosario García Huerta y Francisco Ruiz Gómez (dirs.). Animales simbólicos en la historia. Desde la Protohistoria hasta el final de la Edad Media (187-205). Madrid: Síntesis. 